\title{
Cognitive Control and Lexical Access in Younger and Older Bilinguals
}

\author{
Ellen Bialystok \\ York University
}

\author{
Fergus Craik \\ Rotman Research Institute
}

\author{
Gigi Luk \\ York University
}

\begin{abstract}
Ninety-six participants, who were younger (20 years) or older (68 years) adults and either monolingual or bilingual, completed tasks assessing working memory, lexical retrieval, and executive control. Younger participants performed most of the tasks better than older participants, confirming the effect of aging on these processes. The effect of language group was different for each type of task: Monolinguals and bilinguals performed similarly on working memory tasks, monolinguals performed better on lexical retrieval tasks, and bilinguals performed better on executive control tasks, with some evidence for larger language group differences in older participants on the executive control tasks. These results replicate findings from individual studies obtained using only 1 type of task and different participants. The confirmation of this pattern in the same participants is discussed in terms of a suggested explanation of how the need to manage 2 language systems leads to these different outcomes for cognitive and linguistic functions.
\end{abstract}

Keywords: bilingualism, aging, executive control, lexical retrieval, working memory

There is now persuasive evidence that the central nervous system in humans retains a significant degree of plasticity and remains responsive to experience throughout adulthood (Steven \& Blakemore, 2004). Although this plasticity has primarily been documented for motor skills (Karni et al., 1995; Pascual-Leone et al., 1995), evidence for the modifying effect of experience on the structure or organization of cognitive processes has also been accumulating. For example, C. S. Green and Bavelier (2003) reported that individuals who play video games had faster response times on attention tasks and better visual processing than nonplayers who were otherwise comparable. In another example, Maguire et al. (2000) found that London taxi drivers with extensive training in route finding had enlarged portions of the hippocampi devoted to spatial processing. Gaser and Schlaug (2003) used voxel-based morphometry to compare professional musicians, amateur musicians, and nonmusicians; they found increased gray matter density for professional musicians with smaller increases for amateur musicians in regions of the motor, auditory, and visual cortex. They interpreted these results as evidence for use-dependent structural change and showed as well that the degree of change is calibrated to the degree of experience. Similarly, Mechelli et al. (2004) found increased density in gray and white matter in the left inferior parietal cortex of early bilinguals that corresponded to

Ellen Bialystok and Gigi Luk, York University, Toronto, Ontario, Canada; Fergus Craik, Rotman Research Institute, Toronto, Ontario, Canada.

This work was supported by Canadian Institutes of Health Research Grant MOP-57842 to Ellen Bialystok and Fergus Craik. We thank Jeni Pathman for her assistance in carrying out the study.

Correspondence concerning this article should be addressed to Ellen Bialystok, Department of Psychology, York University, 4700 Keele Street, Toronto, Ontario M3J 1P3, Canada. E-mail: ellenb@yorku.ca learning a second language, with greater density increases as proficiency in the second language increased.

It seems then that a variety of specialized activities can give rise to changes in the underlying brain structures and processes. In the cases described above, however, the neural changes support the specific skills that the person has learned; a further question concerns the possibility that activity-driven brain changes can benefit activities other than those involved in the original training. That is, are there circumstances in which the effects of extended practice generalize to improve performance on related activities? Recent evidence suggests a positive answer to this question; work on the concept of cognitive reserve, for example, has shown that involvement in stimulating intellectual activities protects against cognitive decline, despite the presence of relevant brain pathology (Stern, 2002). In a recent review, Valenzuela and Sachdev (2006a) assessed the evidence on the relation between mental activity and dementia and reported that "six large longitudinal studies have now found that increased levels of leisure and mental activity in late life are associated with an approximate $50 \%$ lower incidence of dementia" (p. 450). In a further article, the same authors conducted a meta-analysis involving over 47,000 individuals and concluded that higher levels of brain reserve were related to decreased rates of cognitive decline in old age (Valenzuela \& Sachdev, 2006b). These conclusions are not universally accepted, however; for example, Salthouse (2006) has pointed out that individuals with better functioning brains may be the ones to participate more fully in stimulating activities.

Consistent with the generally positive evidence for plasticity in cognitive function, a set of studies has demonstrated that bilingualism exerts systematic effects on cognitive performance. The nature of those effects, however, is less clear. In one set of studies, bilingualism has been shown to accelerate the development of executive control in children (Bialystok, 2001; Carlson \& Melt- 
zoff, 2008) using nonverbal control tasks such as the flanker task (Mezzacappa, 2004; Yang, Shih, \& Lust, 2005), perceptual analysis (Bialystok \& Shapero, 2005), and rule switching (Bialystok \& Martin, 2004) but not tasks based on withholding responses, such as delay of gratification (Carlson \& Meltzoff, in press). These effects persist into adulthood (Costa, Hernandez, \& SebastiánGallés, 2008) and appear to protect bilingual older adults against the decline of those processes in older age (Bialystok, Craik, Klein, \& Viswanathan, 2004; Bialystok, Craik, \& Ryan, 2006). Moreover, the difference in executive control between monolinguals and bilinguals is larger in older age because the normal decline of these processes with aging is attenuated for bilinguals. Across the lifespan, therefore, bilingualism boosts the development and postpones the decline of executive control on a variety of tasks. Of note, these effects were found in tasks that were nonverbal and were not obviously related to linguistic processing.

In contrast to these benefits, other studies have shown that bilingualism is associated with decrements in some abilities relative to monolingual controls. For example, research investigating linguistic performance has reported vocabulary deficits for fluently bilingual children (Oller \& Eilers, 2002), increased frequency of tip-of-the-tongue states in adults (Gollan \& Silverberg, 2001), longer naming times for bilingual adults (Gollan, Montoya, Fennema-Notestine, \& Morris, 2005), more errors in picture naming (Roberts, Garcia, Desrochers, \& Hernandez, 2002), reduced scores on letter and category fluency tests (Gollan, Montoya, \& Werner, 2002; Rosselli et al., 2000), and poorer word identification through noise (Rogers, Lister, Febo, Besing, \& Abrams, 2006). Gollan, Fennema-Notestine, Montoya, and Jernigan (2007) found that naming difficulties for bilinguals persist into older age; however, unlike the research on the executive control advantages for bilinguals, it does not appear that the magnitude of the bilingual disadvantage on these linguistic skills changes with aging.

Although there is some debate about the underlying reason for the bilingual disadvantage in lexical retrieval, substantial agreement exists that there is parallel activation of both languages when bilinguals are using one of them (Beauvillain \& Grainger, 1987; Brysbaert, Van Dyck, \& Van de Poel, 1999; Colomé, 2001; Costa, 2005; De Groot, Delmaar, \& Lupker, 2000; Dijkstra, Grainger, \& van Heuven, 1999; D. W. Green, 1998; Hermans, Bongaerts, De Bot, \& Schreuder, 1998; Jared \& Kroll, 2001; Rodriguez-Fornells et al., 2005; Van Hell \& Dijkstra, 2002). More recent evidence for this joint interaction has isolated specific effects on phonological production in the target language (Costa, Roelstraete, \& Hartsuiker, 2006) and shown the persistence of such influences even for two languages that are written in different types of writing systems (Hoshino \& Kroll, 2008). This joint activation contributes to how lexical items are selected, leading to both facilitation and interference depending on the relation between the words (Costa, 2005). Moreover, within monolingual processing, there is other evidence that lexical retrieval becomes more difficult with aging, especially if there is competition from distracting cues (Burke, MacKay, Worthley, \& Wade, 1991; Burke \& Shafto, 2008; Van der Linden et al., 1999; Wingfield \& Stine-Morrow, 2000), but at present there is no evidence that the magnitude of these changes is different for monolinguals and bilinguals.

The linguistic deficit for bilinguals appears to be confined to situations requiring rapid retrieval of specific lexical items and is not found in linguistic or conceptual processing more generally.
For example, Gollan and colleagues (2005) showed that SpanishEnglish bilinguals (many of whom stated that English was their stronger language) named pictures in English more slowly than English monolinguals, but participants in both groups classified the pictures as natural or human-made equally rapidly. Thus, the bilingual deficit does not appear to affect access to semantic information.

In spite of agreement that both languages are active and influence each other in bilingual speech, there are different explanations for how that cross-language interaction affects language production. Costa and colleagues accept that both languages are active (Costa, Roelstraete, \& Hartsuiker, 2006) and that there is a benefit to cognitive control from language management in bilinguals (Costa et al., 2008) but reject the notion that the unwanted language is inhibited (Costa, Caramazza, \& Sebastián-Gallés, 2000). However, the role of inhibition of the unwanted language is supported in research by Meuter and Allport (1999) using a Stroop task and by Levy, McVeigh, Marful, and Anderson (2007) using retrieval-induced forgetting of a dominant language. Gollan and colleagues also agree that both languages are active (Gollan et al., 2002, p. 563; Gollan \& Kroll, 2001) but argue for a connectionist architecture in which access to specific lexical items in each language is determined by connection strength (Gollan \& Brown, 2006). For all these models, therefore, there is agreement that lexical access is more difficult for bilinguals and that both languages of the bilingual are active and interact during speech production in either language, creating the need for some type of attention or selection.

One of the essential cognitive abilities underlying all these skills, including executive functioning and linguistic processing, is working memory. Working memory is completely integrated into descriptions of executive processing and is usually identified as one of its essential components (Miyake \& Shah, 1999). This relationship is equally true for linguistic processes, where studies have consistently identified working memory as central to such tasks as comprehension of written and spoken text (Gernsbacher \& Faust, 1991; Just \& Carpenter, 1992) and fluency in language production (Rosen \& Engle, 1997). Are there differences in working memory ability for monolinguals and bilinguals? The demands on working memory may be greater for bilinguals, who need to manage two languages, a difference that may shape the function of that system. Michael and Gollan (2005) proposed that inhibition may be the missing link that connects working memory and bilingual processing, implying that bilinguals may exhibit more efficient working memory abilities than monolinguals because the need to manage two language systems requires inhibition of one system while the other language is being used. In this sense, bilingual language use may require more extensive manipulation and control of working memory resources, thereby enhancing the use of those resources for other tasks. In line with this suggestion, Bialystok et al. (2004) found some evidence for superior working memory abilities in bilinguals.

One place to examine the possibility that working memory processes are more efficient in bilinguals than in monolinguals is in the most demanding situation of bilingual language production, namely, simultaneous translation (Christoffels \& de Groot, 2005). In a series of studies, Bajo, Padilla, and Padilla (2000) reported more proficient linguistic processing and better working memory performance for a group of simultaneous interpreters than for 
bilinguals of comparable language proficiency and a monolingual control group, the latter two groups not being different from each other. These results suggest that there is no effect of bilingualism per se on working memory processes but that the special case of simultaneous interpretation carries extraordinary processing demands that result in higher working memory abilities. The direction of causality in this correlation remains to be seen, however. Unlike bilingualism, for which there is little personal choice or selectivity because it is usually determined by circumstances, simultaneous interpreters are highly selected and trained. Therefore it is conceivable that those bilinguals for whom working memory abilities are already high are more likely to choose to work as simultaneous interpreters. To further explore the relation between working memory and bilingualism, we included two working memory tasks in the present study.

In summary, the evidence indicates that bilingualism is associated with advantages in executive control, disadvantages in verbal fluency, and no clear effects on working memory. What could explain this pattern? One possible account is that the same processes underlie executive control and verbal fluency but that in one case they boost performance and in the other they are detrimental. Following from the evidence that the two language systems for fluent bilinguals remain active (citations listed above), the fluent use of one of the languages requires an attentional mechanism that will keep language production focused on the relevant language, ignoring interference from the unwanted language. Various models have addressed this problem using some aspect of inhibitory control as the mechanism, in either a cognitive attention system (D. W. Green, 1998) or connectionist architecture (Dijkstra, 2005). The need for this control stems from lexical conflict, but the mechanism itself is likely a central component of inhibition or of cognitive control generally. Therefore, bilinguals constantly face a conflict in lexical choice that monolinguals do not, making such choices more effortful for bilinguals and performance less efficient. This is manifest as a disadvantage in rapid lexical retrieval. At the same time, the resolution of that ongoing conflict boosts the central control system that monitors attention, making that processing more robust in bilinguals. This constant experience in using attention to resolve conflict in online processing is revealed as a bilingual advantage in executive control.

There is some indirect evidence to support this interpretation. Novick, Trueswell, and Thompson-Schill (2005) argue that one important function of Broca's area is to resolve conflict during lexical processing. In an imaging study using magnetoencephalography in which monolinguals and bilinguals performed the Simon task, fast responses on the conflict trials were associated with activation of such frontal areas as dorsolateral prefrontal cortex for monolinguals, but with increased activation of Broca's area for bilinguals (Bialystok et al., 2005). This pattern indicates a role for Broca's area in resolving nonverbal conflict but also suggests that Broca's area was the most able of the frontal regions to handle the conflict in the bilinguals. The proposal is that the area has been boosted through its constant use in resolving linguistic conflict and is then available for other types of processing, especially those involving conflict.

The paradox in this explanation is that lexical conflict leads to disadvantages in lexical retrieval but to advantages in nonlinguistic cognitive processing. Moreover, these complementary processes interact with aging: The need to resolve lexical conflict is an ongoing problem for bilinguals and does not appear to change with age, but the benefit of that process boosts the general executive control system, protecting it from decline and providing an additional age-related advantage for older bilinguals. A problem in assessing the evidence for the competing effects of executive function advantages and lexical retrieval disadvantages is that the results have always been reported in different studies, using different tasks and different participants. Therefore, the explanation that both are consequences of the same mechanism requires the demonstration that the dissociation between lexical retrieval and attentional control is found in the same participants.

The present study was designed to address these issues by establishing a more complete description of the effects of bilingualism on cognitive processing. Accordingly, we assessed the levels of working memory, executive control, and lexical fluency in the same participants and examined these abilities in younger and older participants to explore their lifespan trajectory. Specifically, we expected to demonstrate again that bilinguals outperform monolinguals in tasks of executive control but are poorer than monolinguals on tasks involving lexical access. Recent work suggests that executive control is not a unitary construct but rather comprises a set of abilities that exhibit some commonalities as well as some specific aspects (e.g., Stuss, Shallice, Alexander, \& Picton, 1995). Similarly, Miyake et al. (2000) have shown that the postulated executive functions of information updating and monitoring, set shifting, and inhibition of prepotent responses are interrelated but clearly separable. For this reason we included several different tests of executive control. Two working memory tasks were also included with a view to collecting further evidence on the effects of bilingualism on this function. On the basis of previous results we expected to find that the advantage in attentional control would increase in older adults but that the disadvantages in lexical retrieval would remain constant. The overall purpose was to produce a comprehensive and integrated description of the ways in which bilingualism affects cognition and how aging modifies those effects across the lifespan.

\section{Method}

\section{Participants}

There were 96 participants divided among 24 young monolinguals (mean age $=20.7$ years), 24 young bilinguals (mean age $=$ 19.7 years), 24 older monolinguals (mean age $=67.2$ years), and 24 older bilinguals (mean age $=68.3$ years). The younger participants were recruited from an undergraduate psychology research pool and received course credit for their participation. These participants all attended the same university and had been completely educated in English, but the bilinguals spoke another language at home. The older participants were volunteers from a senior participant pool and received $\$ 15$ in appreciation for their involvement.

The non-English language of the bilinguals included a wide range of languages. The largest groups of speakers were for French (7), Polish (7), Cantonese (6), and Spanish (4). Other non-English languages included Albanian, Arabic, Croatian, German, Greek, Hebrew, Indonesian, Korean, Latvian, Macedonian, Mandarin, Persian, Filipino, Portuguese, Punjabi, Somali, Tamil, Thai, Yugoslavian, and Ukrainian, with 1 or 2 speakers of each of these 
languages. For the young bilinguals, 14 were immigrants, but all had arrived before they were 6 years old and all of their education had been in English; 11 individuals in this group started speaking English before the age of 3 years. For the older bilinguals, 20 were immigrants and all except 4 had arrived before the age of 12 years, the remainder arriving by the time they were 20 . With this profile, it is difficult to assign the classification of first language (L1) and second language (L2) to the bilinguals in the younger group, especially for those participants who learned English before the age of 3; even if English is the second language acquired for these individuals, the use of English for schooling and social life likely makes it more dominant. For the older adults, English is more likely the L2, but participants have been using both English and their other language for an average of 50 years.

All bilinguals reported using both English and the other language daily. They also rated their proficiency in both English and the non-English language on a 5-point scale marked from poor (0) to excellent (4). The mean rating for speaking ability out of a maximum of 4.0 by the young bilinguals was $3.83(S D=0.39)$ for English and $3.15(S D=0.90)$ for the other language; the corresponding results for the older bilinguals were $3.79(S D=0.41)$ for English and $3.65(S D=0.57)$ for the other language.

Finally, the number of years of formal education was compared across groups. There was no difference in mean education between the young monolinguals, $12.83(S D=1.30)$ years, and young bilinguals, $12.36(S D=0.95)$ years, or between the older monolinguals, $14.43(S D=1.43)$ years, and older bilinguals, 14.25 $(S D=2.45)$ years. However, the older participants had significantly more years of education than the younger ones, $F(3,86)=$ $25.0, p<.0001$, with no difference between language groups.

\section{Tasks}

Three groups of tasks were designed to assess aspects of working memory, lexical access and fluency, and executive control. The working memory tasks consisted of forward and backward Corsi block span and the self-ordered pointing test. We chose nonverbal tasks to avoid confounding working memory ability with an expected verbal disadvantage for bilinguals. The assessment of lexical fluency included the Peabody Picture Vocabulary Test for receptive vocabulary, a Boston naming task, and letter and category fluency tests. Executive control was tested by means of an adaptation of the Simon task, the Stroop color-naming test, and the Sustained Attention to Response Task.

\section{Working Memory}

Forward and backward Corsi blocks. Stimuli consisted of a random array of wooden blocks spread out on a wooden base. Each block contained a number from 1 to 10 painted on the back, not visible from the front. The apparatus was placed between the experimenter and the participant, with the numbers visible only to the experimenter. In the forward condition, the experimenter tapped a sequence of blocks, and participants were required to repeat the sequence in the same order. The sequences began with two blocks and increased by one block after every second trial. Thus there were two trials at each sequence length. Testing continued until participants failed to correctly replicate both trials at a given sequence length. In the backward condition, the sequence demonstrated by the experimenter was repeated by the participant in reverse order, all other procedures being the same. Both conditions began with practice trials. The order of presentation of forward and backward conditions was counterbalanced across participants. The score was the longest sequence length that could be correctly recalled in each condition (Milner, 1971).

Self-ordered pointing. This task (Petrides \& Milner, 1982) was presented in a 12-page booklet, each page containing 12 abstract drawings consisting of lines as well as circles and other random shapes. The same 12 drawings appeared on all the pages, but with each in a different position on each page. Participants were instructed to examine each page of the booklet in order and point to one pattern on each page without pointing to the same pattern more than once. The pages were bound in a plastic binder, and the experimenter flipped the page after a drawing had been selected. The dependent variable was the number of repetitions, or errors, committed in the 12 pages. There were three different booklets, for a maximum total of 36 .

\section{Lexical Access}

Peabody Picture Vocabulary Test (PPVT) III, Form B. This is a standardized test of receptive vocabulary (Dunn \& Dunn, 1997). A test plate containing four pictures is shown, and the experimenter names one of the images. The participant is required to indicate the named image. The plates are arranged in order of increasing difficulty. Testing continues until the participants makes 8 errors out of a predetermined block of 12 trials. Raw scores are converted to standard scores on the basis of the participant's age.

Boston naming task. This task was an adaptation of the Boston Naming Test (Kaplan, Goodglass, \& Weintraub, 1983). The original task consists of 60 line drawings of objects that participants are asked to name. For the modification used in the present study, detailed definitions were created for each of these 60 pictures. For example, "tree" was defined as "A tall woody plant with a trunk, branches, and leaves"; "canoe" was defined as "A small narrow boat with pointed ends." The definitions were pilot tested on a group of young adults to confirm their transparency. As in the standard version, the task was to name the object. In the original task, the difficulty of the items increases through the sequence from 1 to 60 pictures, so the set of 60 was divided into an even-numbered set and an odd-number set. Half of the participants received the even-numbered items as pictures and the oddnumbered items as verbal definitions, and the other half received the reverse pairings.

The purpose of this manipulation was to examine the reported bilingual deficit in lexical retrieval in more detail. We assumed that verbal definitions would necessarily be less precise as cues for the target words than the corresponding pictures of the objects. If the lexical access problem in bilinguals reflects their need for greater contextual support, and the pictures used in the standard version provide more support than definitions, it follows that the bilingual disadvantage in word naming should be greater in the definition condition. If the disadvantage is unaffected by this manipulation, however, such a result would suggest that the bilingual problem is not primarily one of accessibility but rather one of vocabulary size or perhaps reflective of the need to resolve the conflict between two competing solutions. 
Stimuli were put in a PowerPoint presentation (pictures from the original task were scanned, and definitions were written). The experimenter went through each slide with the participant and recorded the response. There was no set time limit, but the maximum time spent on any item was less than 1 min. Participants decided when they did not know an answer and the next slide was shown. Half the participants began with the definitions first, and half began with the pictures. Scores were the total number of correct answers out of 30 for each of the picture and definition conditions. Thus, the total for the task was a score out of 60 .

Category (animal) and letter (FAS) fluency. Participants were told to say as many words as they could that started with the letter $F$ within $1 \mathrm{~min}$. The experimenter timed the task with a stop watch and recorded all the words that were produced. This same procedure was repeated for the letters $A$ and $S$. For the category condition, participants were asked to name as many animals as they could within $1 \mathrm{~min}$. Scores were the total number of unique items, excluding repetitions, produced within the $1 \mathrm{~min}$ allowed for each condition (see Milner, 1964).

\section{Executive Control}

Simon arrows task. This task was based on the stimulusresponse conflict of the Simon task (Simon \& Ruddell, 1967) but used directional arrows as the stimuli and included conditions that varied in their demands for cognitive control. The experiment was instantiated on a Dell laptop using Superlab (Version 2.0.4) software. A mouse pad was affixed to each side of the computer monitor and used to indicate left or right responses. Following the response, the next stimulus appeared after a brief interval of $250 \mathrm{~ms}$.

There were three conditions. The first condition was a control to establish response speed when no additional processing was required. An arrow pointing either left or right appeared in the center of the display, and participants pressed the left or right response key indicating the direction of the arrow as quickly as possible. There were 48 trials in this condition. The second condition, reverse, was based on the same stimuli but the instruction was to press the response key in the direction opposite to that indicated by the arrow. This condition was a measure of response inhibition, or the ability to override a habitual response to a familiar stimulus. There were 48 trials in this condition. In the third, conflict condition, the arrows were presented on the left or right sides of the display, creating congruent trials when the direction and position corresponded and incongruent trials when they conflicted. The instruction was to press the response key indicating the direction that the arrow was pointing, irrespective of the position. This condition contained 96 trials including 48 congruent and 48 incongruent trials presented in random sequence.

Participants were given instructions and examples with feedback before each block. They were told to respond as quickly as possible without making errors. The experiment consisted of six blocks of trials (two blocks for each condition) administered in two presentation orders that were counterbalanced across participants. The first order was control, reverse, conflict, reverse, conflict, control. The second order was control, conflict, reverse, conflict, reverse, control. Within the conflict trials, half were congruent and half were incongruent. For the analyses, data were collapsed across the two repetitions of each block type.
Stroop color-naming task. This task was a version of the standard Stroop color-naming paradigm (Stroop, 1935). The stimuli were the color names red, green, and blue, printed in capital letters in 100-point Arial font, presented in the center of the screen. The trial began with a fixation cross presented for $300 \mathrm{~ms}$, followed by a $250-\mathrm{ms}$ sound file "ding." The purpose was to provide a marker for each new trial on the digital tape that was recording the session. The stimulus appeared immediately after the ding, and participants responded into a voice key. The response was recorded for reaction time by the Superlab program. The accuracy was determined at the end of the session by replaying the digital tape against a checklist of the correct responses. There was a 200-ms interval after the response before the fixation cross for the next trial appeared.

Four conditions were presented in counterbalanced order. The first condition was a control for color-naming speed in which a sequence of $X \mathrm{~s}$ (in the same font as the words in the other conditions) was presented in one of the target colors and participants named the font color as rapidly as possible. The second condition was the word-reading control, in which each of the target color words was presented in black font and the task was to read the word as quickly as possible. The third was a congruent colornaming condition in which the word and font color corresponded. Finally, the Stroop condition presented the color names in conflicting font colors, and participants named the font color as quickly as possible.

The experiment included eight blocks of 24 trials each, consisting of two blocks for each of the four conditions. The first four blocks were presented in one of four orders, each beginning with one of the conditions-color, word, congruent, Stroop-then representing the same blocks in reverse order. Thus, the first order was color, word, congruent, Stroop, Stroop, congruent, word, color; the second was word, congruent, Stroop, color, color, Stroop, congruent, word; and so on. The presentation order was counterbalanced across participants.

Sustained Attention to Response Task (SART; Robertson, Manly, Andrade, Baddeley, \& Yiend, 1997). The SART is a measure of sustained attention that discriminates traumatic brain-injured patients from normal controls matched on age, gender, and IQ. In the Robertson et al. (1997) study, the traumatic brain-injured patients performed less well than controls on the SART, the Stroop task, and the Wisconsin Card Sorting Test, but SART performance did not correlate significantly with performance on these other two measures of executive control, suggesting that SART is a specific measure of sustained attention as opposed to a measure of general inhibitory ability.

The digits from 1 to 9 were presented one at a time in the center of the screen in random order. The participant was asked to press the response key (the space bar on the keyboard) as quickly as possible, except if the number 3 appeared. When they saw the number 3, participants were told, they should not press anything and wait for the next number. Each trial began with a mask, consisting of a colored square that was presented for $500 \mathrm{~ms}$. After a 250-ms interval, one of the nine digits appeared and remained on the screen until the response key was pressed. The response initiated the next trial. When the stimulus was the number 3 , the next trial began after $2,000 \mathrm{~ms}$. There were 225 trials in total, arranged in 25 blocks of 9 trials each. 


\section{Results \\ Working Memory Tasks}

The results for the working memory tasks are shown in Table 1. For the Corsi block task, the younger participants recalled longer strings of blocks than older participants, $F(1,92)=6.49, M S E=$ $1.1, p<.01$, with no significant difference between participants in the two language groups, $F(1,92)=2.10, n s$, but an interaction of language group and age, $F(1,92)=5.16, M S E=1.1, p<.03$. For the younger participants, the bilinguals recalled more items than the monolinguals, $F(1,46)=5.64, M S E=1.2, p<.02$, but the performance of monolinguals and bilinguals did not differ in the older group $(M S E=0.9, F<1)$. The forward span condition was easier than the backward span, $F(1,92)=50.70, M S E=0.5, p<$ .0001 , and this difference interacted with age, $F(1,92)=13.77$, $M S E=0.5, p<.0004$, reflecting the fact that the discrepancy was larger for the older participants, $F(1,46)=105.45, M S E=0.3$, $p<.0001$, than for younger ones, $F(1,46)=4.03, M S E=0.7$, $p<.05$. The difference between forward and backward span did not interact with language or with the interaction of age and language (both $F_{\mathrm{s}}<1$ ).

The dependent variable for the self-ordered pointing task was the number of repetition errors participants made across the trials. These data are also reported in Table 1. A two-way analysis of variance (ANOVA) for age and language group indicated only a difference for age group, $F(1,92)=35.58, M S E=6.9, p<.0001$, in which older participants made more errors than younger ones. There was no effect of language group or the interaction of age and language group (both $F \mathrm{~s}<1$ ).

\section{Verbal Tasks}

The results for the verbal tasks are shown in Table 2. For the PPVT vocabulary scores standardized for age, monolinguals scored higher than bilinguals, $F(1,92)=40.06, M S E=128, p<$ .0001 , with no difference between age groups and no interaction of age and language. Because the scores are standardized for age, it is not surprising that age has no effect on the results. The monolingual advantage was again found for fluency tests, in which monolinguals generated more items than bilinguals, for both letter, $F(1,92)=18.30, M S E=104, p<.0001$, and category conditions, $F(1,92)=11.41, M S E=21.9, p<.001$. This task also revealed an effect of age in which young participants generated more items than older participants, again for both letter, $F(1,92)=8.08$, $M S E=104, p<.005$, and category tests, $F(1,92)=21.14$, $M S E=21.9, p<.0001$. There was no interaction between age and

Table 1

Mean Score (and Standard Deviation) for the Working Memory Tasks by Age Group and Language Group

\begin{tabular}{lccr}
\hline & & \multicolumn{2}{c}{ Corsi block span } \\
\cline { 3 - 4 } \multicolumn{1}{c}{ Group } & $\begin{array}{c}\text { Self-ordered pointing } \\
\text { mean errors }\end{array}$ & Forward & Backward \\
\hline Young monolinguals & $5.0(2.8)$ & $3.3(0.9)$ & $2.8(1.2)$ \\
Young bilinguals & $5.4(2.5)$ & $3.8(1.2)$ & $3.5(0.7)$ \\
Older monolinguals & $8.4(2.8)$ & $3.5(0.8)$ & $2.5(0.7)$ \\
Older bilinguals & $8.5(2.4)$ & $3.5(0.8)$ & $2.3(0.7)$ \\
\hline
\end{tabular}

language in either task. Similarly, in the Boston naming task, monolinguals outperformed bilinguals in both the picture, $F(1$, $92)=28.44, M S E=10.2, p<.0001$, and definition versions, $F(1$, $92)=41.21, M S E=11.9, p<.0001$. In this case, there was an age effect only in the definition condition, $F(1,92)=5.32, M S E=$ $11.9, p<.02$, where older participants outperformed younger ones, with no interaction of age and language. This replicates previous research showing maintained and sometimes increased vocabulary knowledge with age (see Burke \& Shafto, 2008, for a review).

\section{Executive Control Tasks}

The mean error rate by all groups for all conditions of the Simon task was less than $1 \%$. An ANOVA for age group and language group showed that the rate did not differ on any factor (all $F \mathrm{~s}<1$ ). The mean reaction times (RTs) by age and language group for this task are shown in Figure 1. The results for the conditions with central presentations (Figure 1a) were submitted to a three-way ANOVA for age, language, and direction (control or reverse). Older participants were slower than younger ones, $F(1,89)=$ 43.85, MSE $=54,028, p<.0001$, with no difference between the language groups and no interaction of language and age $\left(F_{\mathrm{s}}<1\right)$. The reverse direction condition took longer to perform than the control condition, $F(1,89)=80.07, M S E=23,512, p<.0001$, an effect that interacted with age group, $F(1,89)=29.66, M S E=$ $23,512, p<.0001$, because the difference between the control and reverse conditions was greater for the older participants (324 ms) than for the younger ones $(79 \mathrm{~ms})$. There was no effect of language and no significant interaction. Figure 1a shows that control RTs were substantially higher for older than for younger participants, so to allow for this difference in baseline we also carried out an analysis on the percentage increase in RTs from control to reverse conditions. The resulting ANOVA yielded no effect of language group but a significant effect of aging, $F(1,89)=31.24, M S E=$ $1,337, p<.0001$. The age by language interaction did not reach significance, although the percentage increase for the older bilinguals was less than that for the older monolinguals (52\% and $76 \%$, respectively). The percentage increase analysis thus replicated the effects found using the simple arithmetic difference between reverse and control.

The results for the conditions with lateral presentations (Figure 1b) were analyzed by a three-way ANOVA for age, language, and trial type (congruent or incongruent). The older participants were slower than younger ones, $F(1,92)=69.82, M S E=32,142$, $p<.0001$, but there was no difference between the language groups, and no age by language interaction $\left(F_{\mathrm{s}}<1\right)$. As expected, incongruent trials were slower than congruent trials for all participants, $F(1,92)=8.48, M S E=2,857, p<.005$. There was a three-way interaction of age, language, and congruence, $F(1$, $92)=5.64, M S E=2,857, p<.02$. The source of the interaction is that the difference between congruent and incongruent trials was not significant for the older bilinguals $(F<1)$, as it was for participants in the other three groups. Another way of considering this difference is in terms of the Simon effect, defined as the difference in RT between congruent and incongruent trials. The mean Simon effect was $8.2 \mathrm{~ms}(S D=20.2 \mathrm{~ms})$ for young monolinguals, $22.3 \mathrm{~ms}(S D=35.2 \mathrm{~ms})$ for young bilinguals, $60.7 \mathrm{~ms}$ $(S D=143.1 \mathrm{~ms})$ for older monolinguals, and $0.2 \mathrm{~ms}(S D=7.7$ 
Table 2

Mean Score (and Standard Deviation) by Age and Language Group for the Peabody Picture Vocabulary Test (PPVT), Boston Naming Task, and Category Fluency Task From the Verbal Task Battery

\begin{tabular}{|c|c|c|c|c|c|}
\hline \multirow[b]{2}{*}{ Group } & \multirow[b]{2}{*}{ PPVT } & \multicolumn{2}{|c|}{ Boston naming } & \multicolumn{2}{|c|}{ Fluency } \\
\hline & & Picture & Definition & Letter & Category \\
\hline Young monolinguals & $122.3(9.3)$ & $26.9(2.2)$ & $25.5(3.2)$ & $49.8(7.4)$ & $23.3(5.4)$ \\
\hline Young bilinguals & $109.2(10.3)$ & $24.0(4.6)$ & $20.4(4.3)$ & $42.4(11.1)$ & $21.3(3.8)$ \\
\hline Older monolinguals & $119.5(10.2)$ & $27.1(2.3)$ & $26.5(2.9)$ & $45.4(7.7)$ & 20.1 (3.9) \\
\hline Older bilinguals & $103.3(14.9)$ & $23.0(3.0)$ & $22.5(3.3)$ & 34.9 (13.9) & $15.7(5.4)$ \\
\hline
\end{tabular}

ms) for older bilinguals. A two-way ANOVA on these scores for age and language indicated an interaction of the two factors, $F(1$, $92)=5.64, M S E=5,715, p<.02$ : The magnitude of the difference was the same for the monolinguals and bilinguals in the younger group, $F(1,46)=2.67, n s$, but larger for the monolinguals in the older group, $F(1,46)=4.27, M S E=10,278, p<.04$. An analysis of the percentage increases from congruent to incongruent trials yielded the same pattern of results. The ANOVA
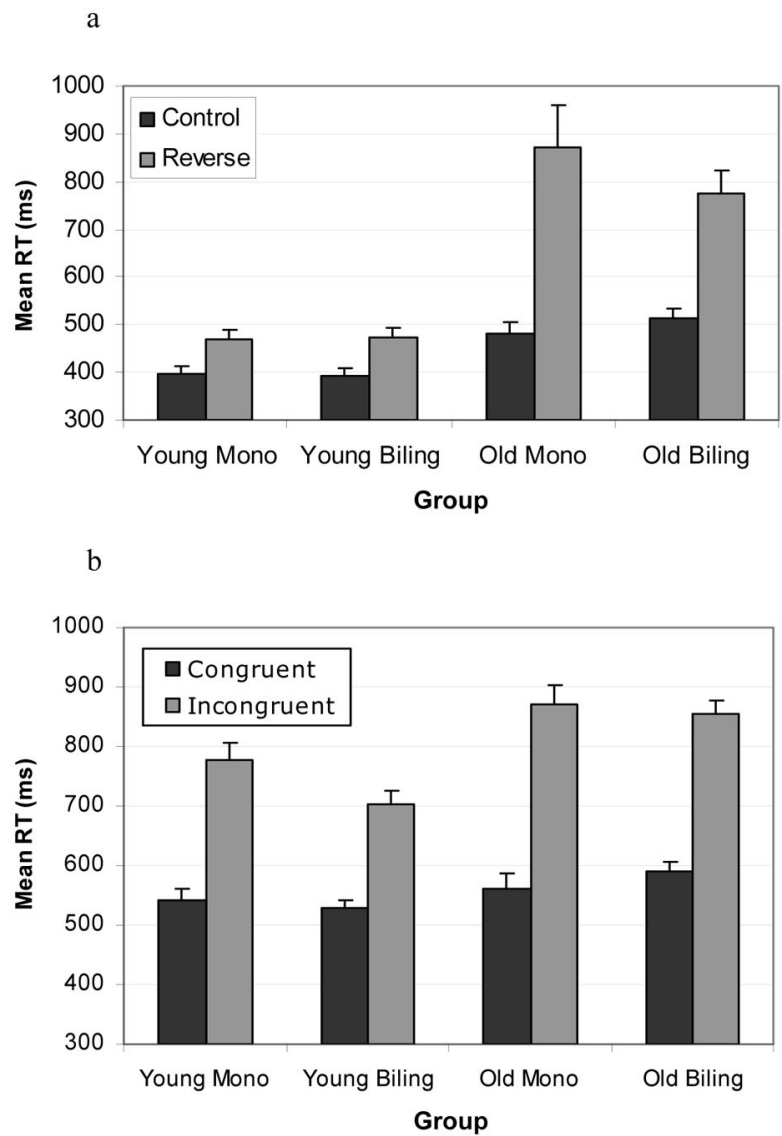

Figure 1. Mean reaction time (RT) and standard error in the Simon arrows task by age and language group for (a) central presentations of stimuli showing control and reverse trials and (b) side presentations of stimuli showing congruent and incongruent trials. Mono = monolinguals; biling $=$ bilinguals showed no reliable effects of either age or language (both $F$ s $<$ $1.80)$ but a significant interaction between age and language, $F(1$, $89)=6.90, M S E=114, p=.01$, confirming that the results held for proportional changes as well as for simple differences.

As with the Simon task, the data from the Stroop task were examined in terms of both errors and RTs. The errors were negligible in all conditions except the incongruent Stroop block. In this case, the error rate was $2.1 \%$ for the young monolinguals and less than $1 \%$ for all other groups. A two-way ANOVA revealed effects of both age, $F(1,92)=21.11, M S E=0.4, p<.0001$, and language group, $F(1,92)=10.77, M S E=0.4, p<.002$, qualified by the interaction between these factors, $F(1,92)=5.28, M S E=$ $0.4, p<.02$, reflecting the high error rate for the young monolinguals.

The RT data for the two control conditions in the Stroop task are reported in Figure 2a. Although the color and word controls were presented in separate blocks, the data were analyzed together. A three-way ANOVA for age, language, and control condition (color or word naming) indicated slightly faster response times by younger participants, $F(1,92)=3.78, M S E=21,739, p=.05$, with no difference between the two language groups $(F<1)$ and no interactions. Consistent with the literature, word-naming times were faster than color-naming times, $F(1,92)=165.24, M S E=$ $1,582, p<.0001$. For the color-word conditions, response times from the congruent and incongruent conditions, presented in Figure $2 \mathrm{~b}$, were also analyzed together. Younger participants had faster RTs than older ones, $F(1,92)=13.55, M S E=23,094, p<$ .0004 , with no difference between the language groups $(F<1)$. The Stroop effect is the RT difference between the congruent and incongruent trials. Overall, the congruent trials were faster than the incongruent trials, $F(1,92)=716.07, M S E=4,046, p<.0001$, an effect that interacted with both age, $F(1,92)=19.31, M S E=$ $4,046, p<.0001$, and language group, $F(1,92)=7.82, M S E=$ $4,046, p<.006$. As seen in Figure $2 b$, these interactions were caused by a larger Stroop effect for older participants and for monolingual participants. A further analysis of the percentage increase in RT from congruent to incongruent trials yielded the same pattern of results. The ANOVA showed main effects of age, $F(1,92)=10.87, M S E=344, p<.002$, and language, $F(1,92)=$ $8.76, M S E=344, p<.01$, thereby confirming the reliability of the larger Stroop effect for older and monolingual participants. The interaction of age and language was not significant $(F<1)$.

Another way of considering the color-naming results is in terms of the facilitation associated with the word printed in its own color, and the cost associated with the word printed in another color, 
relative to the neutral color-naming condition when no word is present. These comparisons indicate the extent to which the word in the Stroop trials can be attended to when it is helpful (congruent trials) and ignored when it is misleading (incongruent trials). These contrasts provide a more detailed description of attentional control, including both attention toward helpful cues and away from interfering stimulus cues. The mean RTs for facilitation, calculated as the RT difference between congruent and neutral color-naming trials, and cost, calculated as the RT difference between incongruent and neutral trials, are presented in Figure 3. A three-factor ANOVA involving age, language group, and contrast (facilitation or cost) was carried out on these data; for the purposes of this analysis, both facilitation and cost scores were treated as positive numbers. The ANOVA revealed significant effects of age, $F(1$, $92)=19.31, M S E=4,046, p<.0001$, and language group, $F(1$, $92)=7.82, M S E=4,046, p<.006$. There was an effect of contrast, $F(1,92)=128.5, M S E=5,210, p<.001$, because the magnitude of cost was greater than that of facilitation. There were also interactions of contrast and age, $F(1,92)=12.65, M S E=$ $5,210, p<.006$, because age differences were greater for cost than for facilitation, and of contrast and language, $F(1,92)=9.36$, $M S E=5,210, p<.003$, because the language differences were also greater for cost than for facilitation. In addition, there was a

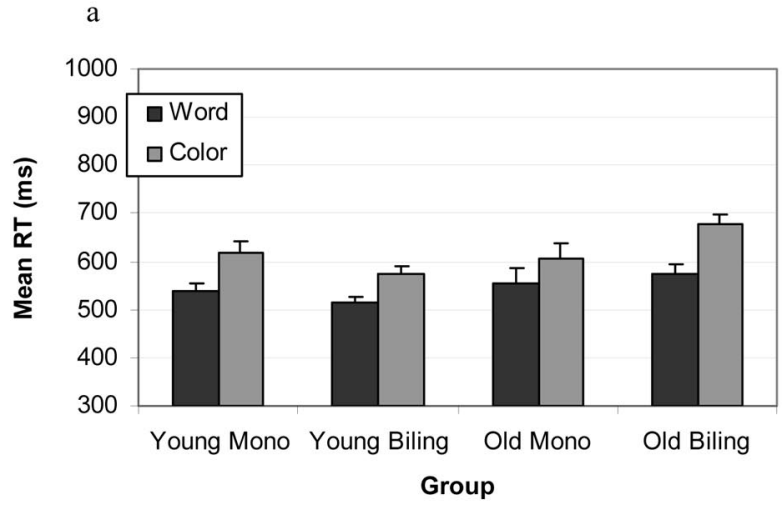

b

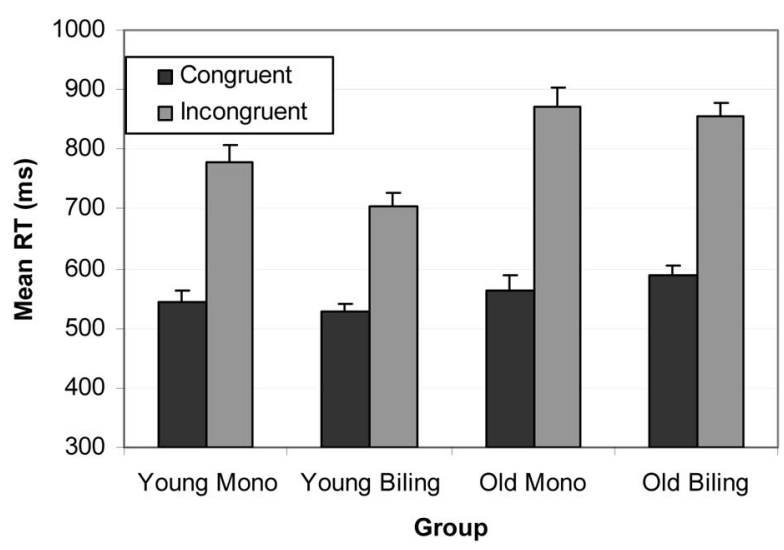

Figure 2. Mean reaction time (RT) and standard error in the Stroop color-naming task for (a) word and color control trials and (b) congruent and incongruent Stroop condition trials. Mono $=$ monolinguals; biling $=$ bilinguals.

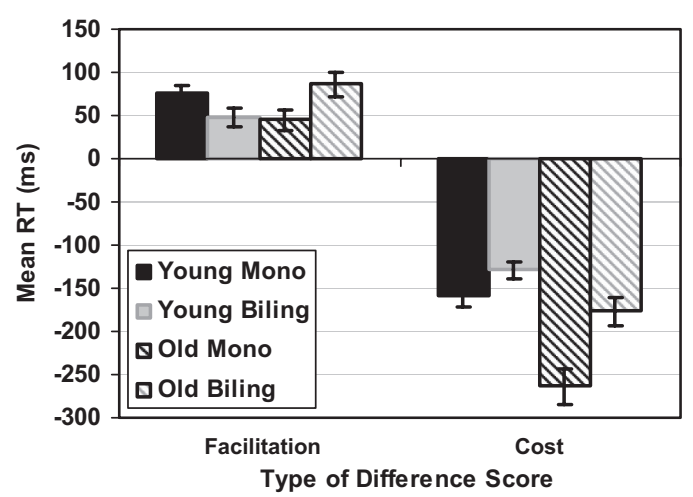

Figure 3. Mean reaction time (RT) and standard error for facilitation and cost in the Stroop task. The values are mean differences from baseline $(0$ $\mathrm{ms})$ calculated as the average time to name colors from neutral stimuli $(X \mathrm{~s})$. Mono $=$ monolinguals; biling $=$ bilinguals.

three-way interaction of age, language, and contrast, $F(1,92)=$ 9.49, $M S E=5,210, p<.002$; whereas both younger and older bilinguals sustained smaller costs than their monolingual peers, facilitation effects were larger only for the older bilinguals (Figure 3). To compensate for age differences in baseline RTs, percentage decreases in RT from color-naming to congruent Stroop trials (facilitation) and percentage increases in RT from color-naming to incongruent Stroop trials (cost) were calculated and analyzed separately. For facilitation, the ANOVA revealed no effects of age or language (both $F \mathrm{~s}<1$ ) but a significant interaction of age and language, $F(1,92)=8.75, M S E=72, p<.005$. For cost, the analysis showed strong effects of age, $F(1,92)=15.98, M S E=$ $255, p<.0001$; language, $F(1,92)=12.36, M S E=255, p<$ .001 ; and their interaction, $F(1,92)=6.67, M S E=255, p<.01$. Again, these proportional change analyses confirmed the reliability of the patterns shown in Figure 3.

Finally, the size of the Stroop effect is related to the automaticity of word reading, with faster, or more automatic, reading producing more interference and larger Stroop effects (MacLeod, 1991; Meiran, 1996). There is evidence that highly fluent bilinguals read their second language with less automaticity than monolingual native speakers (Favreau \& Segalowitz, 1983; Segalowitz \& Segalowitz, 1993) and that there is automatic activation of the nonrelevant language for bilinguals performing a cross-linguistic Stroop task (Tzelgov, Henik, Sneg, \& Baruch, 1996). It is possible, therefore, that the bilinguals in the present study read the English words less automatically than the monolinguals, thereby diminishing the size of the Stroop effect. Although the bilinguals performed more poorly than the monolinguals on the lexical retrieval tasks, there was no difference between language groups in reading time on the word control condition of the Stroop task. Nonetheless, we investigated the possibility that more subtle group differences may have led to different magnitudes of the Stroop effect. Participants in each of the four groups were divided into fast or slow readers on the basis of a median split of the RT on the word-reading condition for that group. The relevant subgroups to test the hypothesis that automaticity was responsible for the results are the slow monolinguals (because being a slower reader should decrease the conflict) and the fast bilinguals (because being a fast reader should increase the Stroop cost). The mean values of the Stroop effect for these 
Table 3

Mean Reaction Time (and Standard Deviation) for the Stroop Effect for the Whole Sample and Subgroups Created by a Median Split on the Word Reading Control Condition

\begin{tabular}{lll}
\hline & \multicolumn{2}{c}{ Stroop effect (ms) } \\
\cline { 2 - 3 } \multicolumn{1}{c}{ Group } & Whole sample & $\begin{array}{l}\text { Median split } \\
\text { (word speed) }\end{array}$ \\
\hline Young monolinguals (slow half) & $234(87)$ & $254(76)$ \\
Young bilinguals (fast half) & $176(78)$ & $144(79)$ \\
Older monolinguals (slow half) & $309(112)$ & $303(130)$ \\
Older bilinguals (fast half) & $263(78)$ & $254(101)$ \\
\hline
\end{tabular}

subgroups are reported in Table 3. If differences in Stroop effect size were caused by reading speed, then the monolinguals should demonstrate a smaller Stroop effect in this analysis because they have been selected to be the slower readers; if differences in Stroop effect size were caused by bilingualism, then bilinguals will continue to demonstrate a smaller Stroop effect, even considering only the fastest readers. A two-way ANOVA for age and language on the Stroop effect for these subgroups replicated the results found for the whole sample: Younger participants, $F(1,44)=$ 7.59, $M S E=9,859, p<.008$, and bilinguals, $F(1,44)=7.74$, $M S E=9,859, p<.008$, both recorded smaller Stroop effects, with no interaction between these factors.

The mean scores on the SART include the RT to respond to each new stimulus and the number of errors committed by responding when the digit was a 3 . The total possible score is 25 , as the digit 3 appeared once in each of the 25 blocks. Overall, however, very few errors were made by any of the participants: Young monolinguals produced an average of $3.8(S D=3.5)$, young bilinguals produced $4.1(S D=2.7)$, older monolinguals produced $3.1(S D=$ $3.2)$, and older bilinguals produced $5.3(S D=5.4)$. These error rates did not differ by either language group, $F(1,92)=1.92, n s$, or age group $(F<1)$. For RT, younger participants $(M=430 \mathrm{~ms}$, $S D=122)$ were faster than older ones $(M=553 \mathrm{~ms}, S D=104)$, $F(1,92)=28.17, M S E=12,888, p<.0001$, with no difference between language groups $(F<1)$.

Two further issues followed from these analyses. The first was that the monolinguals in both age groups obtained PPVT vocabulary scores that were higher than average (i.e., 100). Therefore, we examined the possibility that these high vocabulary scores affected performance on the other measures by creating subgroups of low and high verbal participants (for the monolinguals) from a median split on PPVT score. None of the comparisons between high and low vocabulary subgroups were different for any of the measures, including Boston naming, $t(46)=-1.48$, $n s$; verbal fluency $(t<1)$; Simon effect, $t(44)=1.56, n s$; Stroop effect $(t<$ $1)$; forward Corsi $(t<1)$; or reverse Corsi $(t<1)$. Therefore, we have no reason to believe that the high PPVT scores of the monolinguals affected other results.

Second, the participants in the two age groups became bilingual at different ages, and this may also have affected outcomes. All of the young bilinguals were fully fluent in both languages by age 6 , but participants in the older group were more mixed. Therefore, we divided the older bilinguals into two subgroups consisting of 12 participants who became bilingual by age 8 and 12 who became bilingual after that, with the oldest participant becoming bilingual at age 20. We compared the scores for the subgroups on the following variables: PPVT vocabulary, $t(22)=-1.75$, $n s$; Boston naming total $(t<1)$; fluency total $(t<1)$; Simon effect $(t<1)$; and Stroop effect, $t(22)=1.00, n s$. These analyses indicate that the age at which English was learned in this group of older bilinguals did not affect the results.

Finally, we examined the relationship among the variables using multivariate analyses. Because the bilinguals showed advantages in control tasks but disadvantages in lexical tasks, it might be predicted that these sets of variables should be related for bilinguals. This prediction follows directly from the hypothesis that the same processes underlie executive control and verbal fluency. However, correlations between the major control and lexical measures showed relatively few significant relations across these domains. The only clear results in this direction came from the older bilinguals, in which there was a negative correlation between performance on the Simon task and on the fluency tasks, $r(24)=$ $-.59, p<.002$, and on the PPVT, $r(24)=-.48, p<.01$. To examine the structure of these tasks more fully we created a biplot to determine the multivariate relationship between the domains of processes, age, and language groups. A biplot on all 96 participants (see Figure 4) represents both variables and observations in a two-dimensional space. This procedure is mainly used for visually interpreting multivariate data and not for providing analyses of statistical significance (Friendly, 2007; Gabriel, 1981).

Five variables from two of the domains, lexical access and control, were included in the biplot: SART scores, Stroop effect, Simon effect, fluency (combining category and letter tasks), and Boston naming totals (combining picture naming and definitions). In the biplot in Figure 4, the data are presented around the centroid (the grand mean of all variables), and the variables are represented as vectors protruding from that centroid. The abscissa and ordinate indicate the first two dimensions, which account for $56 \%$ of the total variation. The cosine of the angles between vectors approximates the correlations between the variables. It is apparent that the executive control measures, Simon and Stroop, are highly correlated and that the proficiency measures, fluency and Boston naming, are also highly correlated. These two clusters form a right angle, which denotes their orthogonality. This pattern suggests (against our initial expectation) that those participants who show greatest access difficulties are not necessarily the ones who show greatest advantages of executive control. However, the SART scores are uncorrelated with the executive control variables but are negatively correlated with the verbal proficiency variables.

\section{Discussion}

Younger and older participants who were monolingual or bilingual completed a battery of tasks measuring working memory, verbal fluency, and executive control. The results showed both general relationships between the two grouping variables, age and bilingualism, on the three domains of tasks and specific effects indicating processing differences on individual tasks. In general, younger participants performed better than older adults on most of the tasks. The effect of language group, in contrast, was different for each of the three sets of tasks: Monolinguals and bilinguals performed largely equivalently on the working memory tasks, monolinguals were better on tasks measuring lexical retrieval, and 


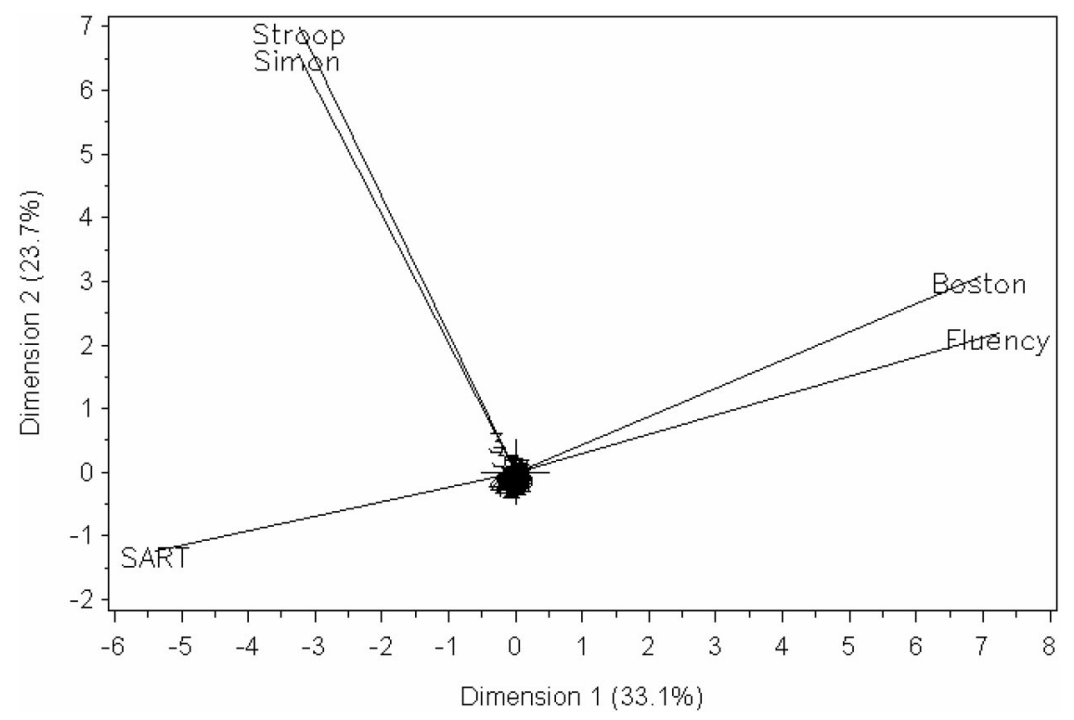

Figure 4. Biplot showing multivariate relationship among five variables. The dimensions indicate the percentage of variance explained by each. These are additive, showing that the model explains $56 \%$ of the overall variance.

bilinguals showed some advantages on measures of executive control. The effect sizes of these results ranged between small and medium in Cohen's (1988) terms; for language effects they ranged from 0.11 to 0.31 , and for age effects they ranged from 0.06 to 0.44 . The advantages and disadvantages of bilingualism are thus not dramatically large; they are however consistently replicable, as demonstrated by an increasing number of reports from different laboratories. We discuss the results of the present study in terms of a comparison of the performance of monolingual and bilingual participants on an extended range of tasks, the implications of finding the pattern of advantages and disadvantages within the same participants, an assessment of the relation between the general factors of access and control, and the available evidence on interactions between bilingualism and aging.

\section{The Monolingual Advantage in Lexical Access}

The results obtained from all three verbal tasks showed consistent monolingual advantages, confirming the pattern reported by Gollan and her colleagues (Michael \& Gollan, 2005). The effect of age was more varied. Because the PPVT scores were standardized according to participant age, this task cannot be used to detect age-related differences in performance if participants in the groups are otherwise comparable. On the fluency tasks, older participants generated fewer items than younger ones in both letter and category conditions, as would be expected for this speeded task. In the Boston naming task, however, picture naming was performed equally well by younger and older participants, but an age effect was found for the more difficult definition condition, in which older participants named more items than younger ones.

There are two possible explanations for the bilingual disadvantage on the lexical tasks. The first follows from the salient difference between monolinguals and bilinguals in that the former group has had approximately twice as much experience in retrieving words in the studied language as the bilingual group, leading to differences in frequency of usage (Gollan et al., 2005, 2007). This explanation is plausible and is consistent with a variety of evidence indicating the role of such frequency effects on performance both in general and in the specific case of second language acquisition (Hernandez \& Li, 2007). Furthermore, the frequency account provides an appealing explanation for the lower vocabulary scores obtained by bilinguals in most research. The second possibility is that the cost in lexical access stems from the need to resolve conflict between competing responses. That is, lexical representations may be intact in bilinguals, but response production may suffer from the need to suppress interference from the unwanted language. This account cannot explain the lower vocabulary scores by bilinguals on the PPVT because that test does not involve any conflict. In that test, a word is provided and the participant simply chooses the picture that depicts the word, so there is no lexical competition and no time pressure to select the correct alternative. However, the conflict resolution account does serve to explain both the disadvantages in lexical retrieval and the advantages in executive control, because both effects are attributed to the same mechanism. The advantage, therefore, is in positing one mechanism for two effects instead of separate explanations for each. Moreover, without appealing to the resolution of conflict in linguistic processing, it is hard to understand why bilinguals would demonstrate consistent advantages in conflict resolution in nonlinguistic processing.

In sum, the battery of verbal tasks indicated a superiority of lexical retrieval for monolinguals. There were no interactions between age and language group for any of the verbal tasks, indicating equivalent effects of aging for individuals in both language groups.

\section{The Bilingual Advantage in Control}

On the basis of our previous results (Bialystok et al., 2004) we expected to find a bilingual advantage in control that was greater 
in older participants. The data largely support this expectation, although with some deviations and anomalies. In the Simon paradigm, Figure $1 \mathrm{~b}$ shows that the difference between congruent and incongruent responses was greatest for old monolinguals $(61 \mathrm{~ms})$ and least for old bilinguals $(0.2 \mathrm{~ms})$. This pattern yielded a significant interaction of age and language group, showing greatest levels of control in the old bilingual group as predicted, although the absence of a Simon effect in that group is anomalous. It seems possible that these participants responded cautiously to all stimuli, thereby inflating congruent RTs to the same level as incongruent RTs. Data for the Stroop effect (Figure 2) are more straightforward, yielding main effects of age and language but no interaction. However, the pattern for facilitation and costs (Figure 3) shows that the older bilinguals exhibit greater facilitation and smaller costs relative to their age counterparts, in line with the original prediction.

The SART is apparently based on a different aspect of control and produced results that were different from those in the first two tasks. Consider first the Simon and Stroop tasks. In both cases, the stimuli contain two features: direction and position in the Simon task, and word and color in the Stroop task. The experimental conditions require responding to one of these two features and ignoring the other. Congruent trials are created when the two features converge on the same response (pointing right and presented in the right position, for example), and incongruent trials when the features conflict (pointing right and presented in the left position). Executive control is required to monitor attention to the relevant feature so that the response is chosen on the correct basis, even when the irrelevant feature indicates the opposite response. This type of executive control was described by Bunge, Dudukovic, Thomason, Vaidya, and Gabrieli (2002) as "interference suppression." In contrast, the SART uses simple stimuli that are presented with a rule to either respond or refrain from responding. This type of executive control is required to replace a habitual response with a nonsalient one, or to avoid executing a highly cued response, and was described by Bunge et al. (2002) as "response inhibition." These authors demonstrated that the two kinds of executive control show different developmental trajectories from childhood to adulthood and engage different areas of the prefrontal cortex. Robertson et al. (1997) have also shown that the SART does not correlate significantly with Stroop performance, again suggesting that inhibition is not a unitary construct.

The distinction between interference suppression and response inhibition can be applied to the processes involved in language use for bilinguals. As reported above, research has shown that both languages are active when bilinguals are engaged in using one of them. Therefore, executive control is needed to attend to the representational system corresponding to the language that is required at the moment and avoid attending to the system associated with the other language. This type of control is interference suppression, as described by Bunge et al. (2002). Hence, bilinguals routinely engage interference suppression in the normal course of language production. It is less clear how response inhibition might be recruited by bilinguals in daily language use. Response inhibition is involved when a change in the execution of a response is needed and seems to function at a more motoric level of control. Because bilinguals do not refrain from speaking, there is no reason to think they have more experience in exercising response inhibition than do monolinguals. Therefore, on the basis of the degree of involvement of each of these aspects of executive control in ordinary speech production, it might be expected that bilinguals would have higher levels of interference suppression than monolinguals but similar levels of response inhibition.

In the battery of executive function tasks used in this study, the experimental conditions of the Simon and Stroop tasks required interference suppression, whereas the reverse condition of the Simon task and the SART required response inhibition. Consistent with the preceding analysis, bilinguals performed better than monolinguals on the Simon and Stroop tasks but participants in the two groups performed similarly on the reverse Simon condition and SART task. In the Simon and Stroop tasks, there were no differences between language groups in the control trials but there was a bilingual advantage in the costs of inhibitory trials relative to congruent ones. Thus, in the Simon task there was a smaller Simon effect for older bilinguals, and in the Stroop task, there was a smaller Stroop effect and a smaller cost score compared with the neutral trials for bilinguals in both age groups.

The conclusion that there is a dissociation in the effect of bilingualism on tasks based on interference suppression on the one hand and response inhibition on the other is consistent with other research. In a study by Martin-Rhee and Bialystok (in press, Study 3), 8-year-old children were given the Simon arrows task used in the present study. As in this experiment, monolinguals and bilinguals produced the same RT in the reverse condition but bilinguals performed faster in the experimental condition consisting of congruent and incongruent trials. In a study using a large battery of executive control tasks with 6-year-olds, Carlson and Meltzoff (in press) showed that bilinguals outperformed monolinguals on tasks that clustered on a dimension of "conflict" in a principalcomponents analysis but performed the same as monolinguals on tasks that clustered on a dimension of "delay," the primary feature being the need to refrain from responding. In a study with adults using a behavioral version of an antisaccade task (Bialystok, Craik, \& Ryan, 2006), young monolinguals and bilinguals performed equivalently in an antisaccade condition in which they were required to press a key on the side opposite to stimulus presentation (response inhibition), but bilinguals were faster in a conflict condition where they had to ignore an additional misleading feature, the direction of eye gaze (interference suppression). Finally, a study by Costa et al. (2008) compared monolinguals and bilinguals on the attentional network task developed by Fan, McCandliss, Sommer, Raz, and Posner (2002). This task combines a version of the flanker task with an alerting/orienting cue and has been widely used to assess individual differences in attention. Costa and colleagues found that bilinguals performed better than monolinguals on the components measuring executive control and alerting, but there were no group differences in the orienting function. All these studies are consistent with the results from the present experiment showing bilingual advantages in certain aspects of control but not in others.

Working memory tasks are generally thought to involve executive control functions, so bilingual advantages might be expected. In fact, however, the present working memory tasks revealed clear differences between participants in the two age groups but only minor differences attributable to language group. The only task in which there were language group differences was the Corsi span task, where young bilinguals recalled longer strings than the young monolinguals in both forward and backward span conditions; no 
such language group differences were found in the self-ordered pointing task. Therefore, the primary difference in performance on the working memory tasks was that older participants recalled fewer items than their younger counterparts, with little systematic variation attributable to language experience. The more general question of whether bilingualism affects working memory performance in any task or situation remains somewhat open. Previous studies have sometimes found a bilingual benefit (e.g., Bialystok et al., 2004) and sometimes found no relationship (e.g., Bajo et al., 2000). There are indications that working memory may be a family of related constructs rather than a unitary entity; various tests of working memory do not necessarily correlate with each other (e.g., Daneman \& Tardif, 1987), and this is particularly true of tests tapping spatial as opposed to verbal abilities (Baddeley, 1986). One attractive possibility is that working memory tasks engage common frontal lobe areas working in concert with distinct taskspecific posterior areas (Cowan, 2005). From this perspective it is perfectly possible that different working memory tasks may be differentially affected by bilingualism. We therefore prefer to await further clarifying data before drawing final conclusions.

\section{Relations Between Access and Control}

The biplot analysis shown in Figure 4 confirmed that the two main measures of cognitive control (Simon and Stroop) were strongly related, as were the two tests of lexical access (Boston naming and verbal fluency). Further, these two sets of tasks were unrelated, although the ANOVAs showed that bilinguals performed significantly better than monolinguals in one set but significantly worse in the other. If the bilingual advantage in cognitive control stems from the bilinguals' lengthy experience of having to suppress interference from the nonused language, as suggested by D. W. Green (1998) and Bialystok (2001), and if the bilingual disadvantage in lexical access reflects the same need to resolve conflict between competing lexical items, it might be expected that the control and access measures would correlate negatively within the bilingual groups. That is, those bilingual participants who have developed the most effective control processes (as shown by small Stroop and Simon effects) would also be the ones least affected by lexical competition and would therefore perform well on naming and fluency tests. Such correlations were generally absent in the present data: For the young bilinguals the correlations ranged between -.26 and .03 ; for the old bilinguals the values ranged between -.59 and .23 . However, the absence of correlations does not rule out the possibility that access and control are influenced by a common underlying cause; the effects may exist between bilinguals and monolinguals as groups rather than at the level of individual participants. Nevertheless, the present data leave open the possibility that the control advantage and access disadvantage demonstrated by bilinguals are attributable to different causes.

\section{Effects of Aging}

The results showed a number of predictable age-related effects: Older participants were generally slower on speeded tasks (Table 3 , Figures 1 and 2) and generated fewer items in the fluency tests (Table 2). In the Boston naming task, the younger participants performed less well than their older counterparts in the definition condition but not in the picture-naming condition; we attribute this difference to the greater "retrieval support" provided by pictures (Craik, 1983). There were no age differences in SART errors, although older adults responded less rapidly to the positive stimuli. The older participants also made more errors on the self-ordered pointing task and performed less well on the backward Corsi task, although there were no age differences on the forward Corsi task. Similar effects have been reported previously, so the present results may be taken as confirmation that our participants were representative of their respective age groups.

The age by language interactions are of greater interest. In the case of the bilingual disadvantage in verbal processing, our data show that the effect does not interact with age; the languagerelated deficits in vocabulary size, naming, and fluency were neither larger nor smaller in older adults than in younger adults. These results are thus consistent with those from previous studies (Gollan et al., 2007), but they are somewhat at odds with a frequency account of the lexical access disadvantage in bilinguals. If the effect is due to the more extensive experience of monolinguals with retrieving words in a given language, presumably this language group difference should become more pronounced as the years pass. With regard to cognitive control, Bialystok et al. (2004) found that the magnitude of the Simon effect increased more with age for monolinguals than for bilinguals, a result that was interpreted as showing that bilingualism attenuates the age-related decline in control. This result was replicated in the present data (Figure 1b) for the Simon task, although the data for old bilinguals are somewhat anomalous. The pattern was not obtained for the Stroop effect measured in the standard way (Figure 2b) but was found for the facilitation and cost analysis shown in Figure 3. The data thus provide some support for the notion that the bilingual advantage in cognitive control is enhanced in older adults, although more evidence is required to confirm this point.

\section{Conclusions}

The current study presents a more detailed description of the cognitive effects of bilingualism than those offered previously because it considers levels of functioning from language, memory, and executive processing in the same group of participants and extends that investigation across participants at two stages of the lifespan. Consistent with the results of studies investigating these processes individually, bilinguals were shown to have poorer language knowledge, similar working memory abilities, and superior executive control than monolinguals. These differences were predicted, and observing them in the same participants performing tasks in the three domains confirms the different effects of bilingualism on each domain.

Considering the present results in the context of our own previous findings along with those of Gollan, Costa, and their colleagues, two empirical results now seem well established. The first is the bilingual disadvantage in lexical access and the second is the bilingual advantage in cognitive control. It is possible that the results are attributable to different causes, but the control advantage must be due to some aspect of the bilingual experience, and in our view the necessity to suppress interference from the nonused language is a strong candidate to account for both the advantage in control and the disadvantage in lexical access. 
Our conjecture is that the lexical conflict created by the parallel activation of two language representations is resolved by the same selective attention mechanisms of the frontal lobes that are used in general executive processing. There is some evidence for this claim. Fabbro, Skrap, and Aglioti (2000) reported a case study of a bilingual patient with damage to his left anterior cingulate cortex and frontal cortex who showed no deficits specific to either of his languages but engaged in pathological mixing in which he randomly inserted utterances from the nonrelevant language to monolingual interlocutors. Price, Green, and von Studnitz (1999) and Hernandez, Dapretto, Mazziotta, and Bookheimer (2001) reached similar conclusions using imaging methods on healthy bilinguals and found the control for language switching to reside in the frontal cortex. In a functional MRI study, Rodriguez-Fornells et al. (2005) found that conflict from the two languages on a phoneme monitoring task activated the dorsolateral prefrontal cortex. It appears, therefore, that the involvement of frontal executive processes in bilingual language management fortifies those processes, making them more efficient even for nonverbal tasks. Therefore, in our view the lexical conflict that is produced by the activation of two language systems has the beneficial effect of boosting the control processes used to resolve that conflict but the detrimental effect of reducing the efficiency with which words from either one of the languages can be retrieved.

In addition to consolidating apparently contradictory effects of bilingualism into a single explanation, validating both the advantages to executive control and the deficits to linguistic processing previously reported in the literature, the present results endorse a functional conception of mind in which language and cognitive processes are integrated. The overall framework for this integrated conception is that cognition reflects the interaction of representational systems and control processes carried out in a particular context (Craik \& Bialystok, 2006, 2008). The present results contribute to the argument that the representational and control systems are strongly interrelated. The development of two language systems promotes the further development of control processes to manage the increased representational complexity. In turn, it seems that these improved control abilities are utilized to enhance aspects of general cognitive functioning.

\section{References}

Baddeley, A. D. (1986). Working memory. Oxford, England: Oxford University Press.

Bajo, M. T., Padilla, F., \& Padilla, P. (2000). Comprehension processes in simultaneous interpreting. In A. Chesterman, N. Gallardo San Alvador, \& Y. Gambier (Eds.), Translation in context (pp. 127-142). Amsterdam: Benjamins.

Beauvillain, C., \& Grainger, J. (1987). Accessing interlexical homographs: Some limitations of a language-selective access. Journal of Memory and Language, 26, 658-672.

Bialystok, E. (2001). Bilingualism in development: Language, literacy, and cognition. New York: Cambridge University Press.

Bialystok, E., Craik, F. I. M., Grady, C., Chau, W., Ishii, R., Gunji, A., \& Pantev, C. (2005). Effect of bilingualism on cognitive control in the Simon task: Evidence from MEG. NeuroImage, 24, 40-49.

Bialystok, E., Craik, F. I. M., Klein, R., \& Viswanathan, M. (2004). Bilingualism, aging, and cognitive control: Evidence from the Simon task. Psychology and Aging, 19, 290-303.

Bialystok, E., Craik, F. I. M., \& Ryan, J. (2006). Executive control in a modified anti-saccade task: Effects of aging and bilingualism. Journal of
Experimental Psychology: Learning, Memory, and Cognition, 32, 13411354.

Bialystok, E., \& Martin, M. M. (2004). Attention and inhibition in bilingual children: Evidence from the dimensional change card sort task. Developmental Science, 7, 325-339.

Bialystok, E., \& Shapero, D. (2005). Ambiguous benefits: The effect of bilingualism on reversing ambiguous figures. Developmental Science, 8, 595-604.

Brysbaert, M., Van Dyck, G., \& Van de Poel, M. (1999). Visual word recognition in bilinguals: Evidence from masked phonological priming. Journal of Experimental Psychology: Human Perception and Performance, 25, 137-148.

Bunge, S. A., Dudukovic, N. M., Thomason, M. E., Vaidya, C. J., \& Gabrieli, J. D. E. (2002). Immature frontal lobe contributions to cognitive control in children: Evidence from fMRI. Neuron, 33, 301-311.

Burke, D. M., MacKay, D. G., Worthley, J. S., \& Wade, E. (1991). On the tip of the tongue: What causes word finding failures in younger and older adults. Journal of Memory and Language, 30, 542-579.

Burke, D. M., \& Shafto, M. A. (2008). Language and aging. In F. I. M. Craik \& T. A. Salthouse (Eds.), The handbook of aging and cognition (3rd ed., pp. 373-443). New York: Psychology Press.

Carlson, S. M., \& Meltzoff, A. N. (2008). Bilingual experience and executive functioning in young children. Developmental Science, 11, 282-298.

Christoffels, I. K., \& de Groot, A. M. B. (2005). Simultaneous interpreting: A cognitive perspective. In J. F. Kroll \& A. M. B. de Groot (Eds.), Handbook of bilingualism: Psycholinguistic approaches (pp. 454-479). New York: Oxford University Press.

Cohen, J. (1988). Statistical power analysis for the behavioral sciences (2nd ed.). Hillsdale, NJ: Erlbaum.

Colomé, A. (2001). Lexical activation in bilinguals' speech production: Language-specific or language-independent? Journal of Memory and Language, 45, 721-736.

Costa, A. (2005). Lexical access in bilingual production. In J. F. Kroll \& A. M. B. D. Groot (Eds.), Handbook of bilingualism: Psycholinguistic approaches (pp. 308-325). New York: Oxford University Press.

Costa, A., Caramazza, A., \& Sebastián-Gallés, N. (2000). The cognate facilitation effect: Implications for models of lexical access. Journal of Experimental Psychology: Learning, Memory, and Cognition, 26, 12831296.

Costa, A., Hernandez, M., \& Sebastián-Gallés, N. (2008). Bilingualism aids conflict resolution: Evidence from the ANT task. Cognition, 106, $59-86$.

Costa, A., Roelstraete, B., \& Hartsuiker, R. (2006). The lexical bias effect in bilingual speech production: Evidence for feedback between lexical and sublexical levels across languages. Psychonomic Bulletin \& Review, 13, 612-617.

Cowan, N. (2005). Working memory capacity. Hove, England: Psychology Press.

Craik, F. I. M. (1983). On the transfer of information from temporary to permanent memory. Philosophical Transactions of the Royal Society of London, Series B, 302, 341-359.

Craik, F. I. M., \& Bialystok, E. (2006). Cognition through the lifespan cognition: Mechanisms of change. Trends in Cognitive Sciences, 10, 131-138.

Craik, F. I. M., \& Bialystok, E. (2008). Lifespan cognitive development: The roles of representation and control. In F. I. M. Craik \& T. A. Salthouse (Eds.), The handbook of aging and cognition (3rd ed.). New York: Psychology Press.

Daneman, M., \& Tardif, T. (1987). Working memory and reading skill re-examined. In M. Coltheart (Ed.), Attention \& performance XII (pp. 491-508). London: Erlbaum.

De Groot, A. M. B., Delmaar, P., \& Lupker, S. J. (2000). The processing of interlexical homographs in a bilingual and monolingual task: Support 
for nonselective access to bilingual memory. Quarterly Journal of Experimental Psychology, 53, 397-428.

Dijkstra, T. (2005). Bilingual visual word recognition and lexical access. In J. F. Kroll \& A. M. B. de Groot (Eds.), Handbook of bilingualism: Psycholinguistic approaches (pp. 179-201). New York: Oxford University Press.

Dijkstra, T., Grainger, J., \& van Heuven, W. J. B. (1999). Recognition of cognates and interlingual homographs: The neglected role of phonology. Journal of Memory and Language, 41, 496-518.

Dunn, L. M., \& Dunn, L. M. (1997). Peabody Picture Vocabulary Test-III. Circle Pines, MN: American Guidance Service.

Fabbro, F., Skrap, M., \& Aglioti, S. (2000). Pathological switching between languages after frontal lesions in a bilingual patient. Journal of Neurology, Neurosurgery, and Psychiatry, 68, 650-652.

Fan, J., McCandliss, B. D., Sommer, T., Raz, A., \& Posner, M. I. (2002). Testing the efficiency and independence of attentional networks. Journal of Cognitive Neuroscience, 14, 340-347.

Favreau, M., \& Segalowitz, N. S. (1983). Automatic and controlled processes in the first- and second-language reading of fluent bilinguals. Memory \& Cognition, 11, 565-574.

Friendly, M. (2007). HE plots for multivariate linear models. Journal of Computational and Graphical Statistics, 16, 421-444.

Gabriel, K. R. (1981). Biplot display of multivariate matrices for inspection of data and diagnosis. In V. Barnett (Ed.), Interpreting multivariate data (pp. 147-173). Bath, England: Wiley.

Gaser, C., \& Schlaug, G. (2003). Brain structures differ between musicians and non-musicians. Journal of Neuroscience, 23, 9240-9245.

Gernsbacher, M. A., \& Faust, M. E. (1991). The mechanism of suppression: A component of general comprehension skill. Journal of Experimental Psychology: Learning, Memory, and Cognition, 17, 245-262.

Gollan, T. H., \& Brown, A. S. (2006). From tip-of-the-tongue (TOT) data to theoretical implications in two steps: When more TOTs means better retrieval. Journal of Experimental Psychology: General, 135, 462-483.

Gollan, T. H., Fennema-Notestine, C., Montoya, R. I., \& Jernigan, T. L. (2007). The bilingual effect on Boston Naming Test performance. Journal of the International Neuropsychological Society, 13, 197-208.

Gollan, T. H., \& Kroll, J. F. (2001). The cognitive neuropsychology of bilingualism. In B. Rapp (Ed.), What deficits reveal about the human mind/brain: A handbook of cognitive neuropsychology (pp. 321-345). Philadelphia: Psychology Press.

Gollan, T. H., Montoya, R. I., Fennema-Notestine, C., \& Morris, S. K. (2005). Bilingualism affects picture naming but not picture classification. Memory \& Cognition, 33, 1220-1234.

Gollan, T. H., Montoya, R. I., \& Werner, G. (2002). Semantic and letter fluency in Spanish-English bilinguals. Neuropsychology, 16, 562-576.

Gollan, T. H., \& Silverberg, N. B. (2001). Tip-of-the-tongue states in Hebrew-English bilinguals. Bilingualism: Language and Cognition, 4, 63-83.

Green, C. S., \& Bavelier, D. (2003, May 29). Action video game modifies visual selective attention. Nature, 423, 534-537.

Green, D. W. (1998). Mental control of the bilingual lexico-semantic system. Bilingualism: Language and Cognition, 1, 67-81.

Hermans, D., Bongaerts, T., De Bot, K., \& Schreuder, R. (1998). Producing words in a foreign language: Can speakers prevent interference from their first language? Bilingualism: Language and Cognition, 1, 213-229.

Hernandez, A. E., Dapretto, M., Mazziotta, J., \& Bookheimer, S. (2001). Language switching and language representation in Spanish-English bilinguals: An fMRI study. NeuroImage, 14, 510-520.

Hernandez, A. E., \& Li, P. (2007). Age of acquisition: Its neural and computational mechanisms. Psychological Bulletin, 133, 638-650.

Hoshino, N., \& Kroll, J. F. (2008). Cognate effects in picture naming: Does cross-language activation survive a change of script? Cognition, 106, 501-511.

Jared, D., \& Kroll, J. (2001). Do bilinguals activate phonological repre- sentations in one or both of their languages when naming words? Journal of Memory and Language, 44, 2-31.

Just, M. A., \& Carpenter, P. A. (1992). A capacity theory of comprehension: Individual differences in working memory. Psychological Review, 99, 122-149.

Kaplan, E. F., Goodglass, H., \& Weintraub, S. (1983). Boston naming test. Philadelphia: Lea \& Febiger.

Karni, A., Meyer, G., Jezzard, P., Adams, M. M., Turner, R., \& Ungerleider, L. G. (1995, September 14). Functional MRI evidence for adult motor cortex placidity during motor skill learning. Nature, 377, 155158.

Levy, B. J., McVeigh, N. D., Marful, A., \& Anderson, M. C. (2007). Inhibiting your native language: The role of retrieval-induced forgetting during second language acquisition. Psychological Science, 18, 29-34.

MacLeod, C. M. (1991). Half a century of research on the Stroop effect: An integrative review. Psychological Bulletin, 109, 163-203.

Maguire, E. A., Gadian, D. G., Johnsrude, I. S., Good, C. D., Ashburner, J., Frackowiak, R. S., \& Frith, C. D. (2000). Navigation-related structural changes in the hippocampi of taxi drivers. Proceedings of the National Academy of Sciences, USA, 97, 4398-4403.

Martin-Rhee, M. M., \& Bialystok, E. (in press). The development of two types of inhibitory control in monolingual and bilingual children. Bilingualism: Language and Cognition.

Mechelli, A., Crinion, J. T., Noppeney, U., O’Doherty, J., Ashburner, J., Frackowiak, R. S., et al. (2004, October 14). Structural plasticity in the bilingual brain. Nature, 431, 757.

Meiran, N. (1996). Is reading ability related to activation dumping speed? Evidence from immediate repetition priming. Memory \& Cognition, 24, 41-59.

Meuter, R., \& Allport, A. (1999). Bilingual language switching in naming: Asymmetrical costs of language selection. Journal of Memory and Language, 40, 25-40.

Mezzacappa, E. (2004). Alerting, orienting, and executive attention: Developmental properties and sociodemographic correlates in an epidemiological sample of young, urban children. Child Development, 75, 13731386.

Michael, E. B., \& Gollan, T. H. (2005). Being and becoming bilingual: Individual differences and consequences for language production. In J. F. Kroll \& A. M. B. de Groot (Eds.), Handbook of bilingualism: Psycholinguistic approaches (pp. 389-407). New York: Oxford University Press.

Milner, B. (1964). Some effects of frontal-lobe lobectomy in man. In J. Warren \& K. Akert (Eds.), The frontal granular cortex and behavior (pp. 313-331). New York: McGraw-Hill.

Milner, B. (1971). Interhemispheric differences in the localization of psychological processes in man. British Medical Bulletin, 27, 272-277.

Miyake, A., Friedman, N. P., Emerson, N. J., Witzki, A. H., Howerter, A., \& Wager, T. D. (2000). The unity and diversity of executive functions and their contributions to complex "frontal lobe" tasks: A latent variable analysis. Cognitive Psychology, 41, 49-100.

Miyake, A., \& Shah, P. (1999). Toward unified theories of working memory: Emerging general consensus, unresolved theoretical issues, and future research directions. In A. Miyake \& P. Shah (Eds.), Models of working memory: Mechanisms of active maintenance and executive control (pp. 442-481). New York: Cambridge University Press.

Novick, J., Trueswell, J. C., \& Thompson-Schill, S. L. (2005). Cognitive control and parsing: Reexamining the role of Broca's area in sentence comprehension. Cognitive, Affective and Behavioral Neuroscience, 5, 263-281.

Oller, D. K., \& Eilers, R. E. (Eds.). (2002). Language and literacy in bilingual children. Clevedon, England: Multilingual Matters.

Pascual-Leone, A., Nguyet, D., Cohen, L. G., Brasil-Neto, J. P., Cammarota, A., \& Hallett, M. (1995). Modulation of muscle responses 
evoked by transcranial magnetic stimulation during the acquisition of new fine motor skills. Journal of Neurophysiology, 74, 1037-1045.

Petrides, M., \& Milner, B. (1982). Deficits on subject-ordered tasks after frontal- and temporal-lobe lesions in man. Neuropsychologia, 20, 249262.

Price, C. J., Green, D. W., \& von Studnitz, R. (1999). A functional imaging study of translation and language switching. Brain, 122, 2221-2235.

Roberts, P. M., Garcia, L. J., Desrochers, A., \& Hernandez, D. (2002). English performance of proficient bilingual adults on the Boston Naming Test. Aphasiology, 16, 635-645.

Robertson, I. H., Manly, T., Andrade, J., Baddeley, B. T., \& Yiend, J. (1997). 'Oops!': Performance correlates of everyday attentional failures in traumatic brain injured and normal subjects. Neuropsychologia, 35, $747-758$.

Rodriguez-Fornells, A., van der Lugt, A., Rotte, M., Britti, B., Heinze, H.-J., \& Munte, T. F. (2005). Second language interferes with word production in fluent bilinguals: Brain potential and functional imaging evidence. Journal of Cognitive Neuroscience, 17, 422-433.

Rogers, C. L., Lister, J. J., Febo, D. M., Besing, J. M., \& Abrams, H. B. (2006). Effects of bilingualism, noise, and reverberation on speech perception by listeners with normal hearing. Applied Psycholinguistics, 27, 465-485.

Rosen, V. M., \& Engle, R. W. (1997). The role of working memory capacity in retrieval. Journal of Experimental Psychology: General, 126, 211-227.

Rosselli, M., Ardila, A., Araujo, K., Weekes, V. A., Caracciolo, V., Padilla, M., et al. (2000). Verbal fluency and repetition skills in healthy older Spanish-English bilinguals. Applied Neuropsychology, 7, 1-24.

Salthouse, T. A. (2006). Mental exercise and mental aging: Evaluating the validity of the "use it or lose it" hypothesis. Perspectives on Cognitive Science, 1, 68-87.

Segalowitz, N. S., \& Segalowitz, S. J. (1993). Skilled performance, practice, and the differentiation of speed-up from automatization effect: Evidence from second language word recognition. Applied Psycholinguistics, 14, 369-385.

Simon, J. R., \& Ruddell, A. P. (1967). Auditory S-R compatibility: The effect of an irrelevant cue on information processing. Journal of Applied Psychology, 51, 300-304.
Stern, Y. (2002). What is cognitive reserve? Theory and research application of the reserve concept. Journal of the International Neuropsychological Society, 8, 448-460.

Steven, M. S., \& Blakemore, C. (2004). Cortical plasticity in the adult human brain. In M. S. Gazzaniga (Ed.), The cognitive neurosciences III (pp. 1243-1254). Cambridge, MA: MIT Press.

Stroop, J. R. (1935). Studies of interference in serial verbal reactions. Journal of Experimental Psychology, 18, 643-662.

Stuss, D. T., Shallice, T., Alexander, M. P., \& Picton, T. W. (1995). A multidisciplinary approach to anterior attentional functions. Annals of the New York Academy of Sciences, 769, 191-211.

Tzelgov, J., Henik, A., Sneg, R., \& Baruch, O. (1996). Unintentional word reading via the phonological route: The Stroop effect with cross-script homophones. Journal of Experimental Psychology: Learning, Memory, and Cognition, 22, 336-349.

Valenzuela, M. J., \& Sachdev, P. (2006a). Brain reserve and dementia: A systematic review. Psychological Medicine, 36, 441-454.

Valenzuela, M. J., \& Sachdev, P. (2006b). Brain reserve and cognitive decline: A non-parametric systematic review. Psychological Medicine, 36, 1065-1073.

Van der Linden, M., Hupet, M., Feyereisen, P., Schelstraete, M., Bestgen, Y., Bruyer, R., et al. (1999). Cognitive mediators of age-related differences in language comprehension and verbal memory performance. Aging, Neuropsychology and Cognition, 6, 32-55.

Van Hell, J. G., \& Dijkstra, T. (2002). Foreign language knowledge can influence native language performance in exclusively native contexts. Psychonomic Bulletin \& Review, 9, 780-789.

Wingfield, A., \& Stine-Morrow, E. A. L. (2000). Language and speech. In F. I. M. Craik \& T. A. Salthouse (Eds.), The handbook of aging and cognition (2nd ed., pp. 359-416). Mahwah, NJ: Erlbaum.

Yang, S., Shih, J., \& Lust, B. (2005, April). Exploring cognitive advantages of childhood bilingualism through new tests of executive attention. Poster presented at the biennial meeting of the Society for Research in Child Development, Atlanta, GA.

Received November 7, 2007

Revision received January 29, 2008

Accepted February 18, 2008

\section{E-Mail Notification of Your Latest Issue Online!}

Would you like to know when the next issue of your favorite APA journal will be available online? This service is now available to you. Sign up at http://notify.apa.org/ and you will be notified by e-mail when issues of interest to you become available! 